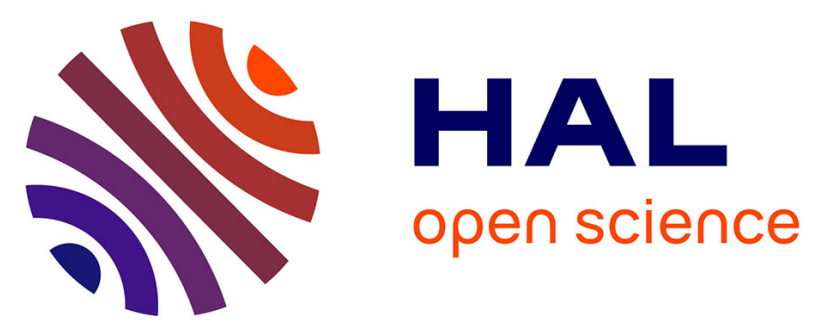

\title{
Early removal of intraperitoneal drainage after pancreatoduodenectomy in patients without postoperative fistula at POD3: Results of a randomized clinical trial
}

J. Dembinski, C. Mariette, J.J. Tuech, F. Mauvais, G. Piessen, D. Fuks, L. Schwarz, S. Truant, C. Cosse, F.R. Pruvot, et al.

\section{To cite this version:}

J. Dembinski, C. Mariette, J.J. Tuech, F. Mauvais, G. Piessen, et al.. Early removal of intraperitoneal drainage after pancreatoduodenectomy in patients without postoperative fistula at POD3: Results of a randomized clinical trial. Journal of Visceral Surgery, 2019, 156, pp.103 - 112. 10.1016/j.jviscsurg.2018.06.006 . hal-03486531

\section{HAL Id: hal-03486531 \\ https://hal.science/hal-03486531}

Submitted on 20 Dec 2021

HAL is a multi-disciplinary open access archive for the deposit and dissemination of scientific research documents, whether they are published or not. The documents may come from teaching and research institutions in France or abroad, or from public or private research centers.
L'archive ouverte pluridisciplinaire HAL, est destinée au dépôt et à la diffusion de documents scientifiques de niveau recherche, publiés ou non, émanant des établissements d'enseignement et de recherche français ou étrangers, des laboratoires publics ou privés.

\section{(ㄷ)(1) $\$$}

Distributed under a Creative Commons Attribution - NonCommerciall 4.0 International 


\title{
Early removal of intraperitoneal drainage after pancreatoduodenectomy in \\ patients without postoperative fistula at POD3: results of a randomized clinical trial
}

Dembinski J ${ }^{1}$, Mariette $\mathrm{C}^{2}$, Tuech J.J ${ }^{3}$, Mauvais $\mathrm{F}^{4}$, Piessen $\mathrm{G}^{2}$, Fuks D ${ }^{1,}$ Schwarz L ${ }^{3}$, Truant $\mathrm{S}^{5}$, Cosse $\mathrm{C}^{1}$, Pruvot F.R ${ }^{5}$, Regimbeau J.M ${ }^{1,6}$

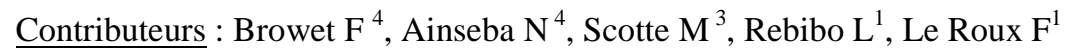

${ }^{1}$ Service de Chirurgie Digestive, CHU, Amiens, France

${ }^{2}$ Service de Chirurgie Digestive et oncologique, CHU Huriez, Lille, France
${ }_{3}$ Service de Chirurgie Digestive, CHU Charles-Nicolle, Rouen, France

${ }^{4}$ Service de Chirurgie Digestive, $\mathrm{CH}$ de Beauvais, Beauvais, France

${ }^{5}$ Service de Chirurgie Hépato Biliaire et Transplantation, CHU Huriez, Lille, France

${ }^{6}$ SSPC (Simplifications des Soins Patients Chirurgicaux Complexes), Unité de Recherche Clinique, CHU, Amiens, France

$\underline{\text { Running head: }}$ short-term drainage after pancreatoduodenectomy

Word count of manuscript: 3242

Number of references: 25

Number of Figures: 1, number of Tables: 6

\begin{abstract}
Abbreviations used: PD: pancreatoduodenectomy; AD: abdominal drainage; RCT: randomized controlled trial; POD: postoperative day; PF: pancreatic fistula; ISGPF: international study group on pancreatic fistula; SSI: surgical site infection; CR-POPF: clinically relevant postoperative pancreatic fistula; COPD: chronic obstructive pulmonary disease; PBD: preoperative biliary drainage; IHPBA: international hépato pancreato biliary association; LOS: length of stay; DP: distal pancreatectomy.
\end{abstract}

\section{Authors stated no financial relationship to disclose.}




\section{ABSTRACT}

Background: To determine whether the timing of removal of abdominal drainage (AD) after pancreatoduodenectomy (PD) influences the 30-day surgical site infection (30-day SSI) rate.

Methods: A multicenter randomized, intention-to-treat trial with two parallel arms (superiority of early vs. standard AD removal on SSI) was performed between 2011 and 2015 in patients with no pancreatic fistula (PF) on POD3 after PD (NCT01368094). The primary endpoint was the 30-day SSI rate. The secondary endpoints were specific post-PD complications (grade BC PF), postoperative morbidity and risk factor of SSI, reoperation rate, 30-day mortality, length of drainage, length of stay and postoperative infectious complications.

Results: One hundred and forty-one patients were randomized: 71 in the early arm, 70 in the standard $\operatorname{arm}(70.2 \%$ of pancreatic adenocarcinomas; $91.5 \%$ of pancreatojejunostomies; $66.0 \%$ of bilateral drainages; feasibility: 39.9\%). Early removal of drains was not associated with a significant decrease of 30-day SSI (14.1\% vs. $24.3 \%, \mathrm{p}=0.12)$. A lower rate of deep SSI was observed in the early arm ( $2.8 \%$ vs. $17.1 \%, \mathrm{p}=0.03)$, leading to a shorter length of stay $(17.8 \pm 6.8 v s .21 .0 \pm 6.1, \mathrm{p}=0.01)$. Grade $\mathrm{BC}$ PF rate $(5.6 \%)$, severe morbidity $(17.7 \%)$, reoperation rate $(7.8 \%)$, 30-day mortality $(1.4 \%)$ and wound-SSI rate $(7.8 \%)$ were similar between arms. After multivariate analysis, the timing of AD removal was not associated with an increase of 30-day SSI (OR=0.74 (95\%CI 0.35-1.13, p=0.38)).

Conclusion: In selected patients with no PF on POD3, early removal of abdominal drainage does not seem to increase or decrease surgical site infection's occurrence. 


\section{INTRODUCTION}

Pancreatoduodenectomy (PD) remains indicated, mainly for cancerous disease. The postoperative mortality has fallen to below $5 \%$ but postoperative morbidity remains as high as $50 \%$ in most recent series $(1,2)$, mainly due to the complexity of pancreatic surgery, but also to the lack of standardization of perioperative measures, which is surprising in the age of enhanced recovery programs after surgery (3) (4).

The use of abdominal drainage (AD) after PD remains a subject of heated, although AD has been mostly abandoned in elective digestive surgery. According to the Cochrane collaboration, there are no guidelines concerning pancreatic surgery ((5), grade A evidence). Early drain removal is not performed in routine practice, as indicated in the study by Melloul et al. (6). In this study, conducted among hepatobiliary surgeons in 55 centers, the drainage rate was $93 \%$ after PD and $11 \%$ of surgeons used no specific criteria for drain removal. In a recent study about different technics of pancreatojejunostomies after PD, all the patient were drained (7).

Studies on drainage after PD present an interesting chronology. In 2001, the randomized controlled trial (RCT) by Conlon et al. (8) suggested that routine placement of drains is unnecessary after PD. Many retrospective studies evaluating PD without drainage reported good results (9) (10), but, in 2014, a RCT by Van Buren et al. had to be stopped early because of excess mortality in the group without drainage. In contrast, a recent randomized controlled trial by Witzigmann et al. (2) showed that drains can be omitted in selected patients after PD, but at the price of reduced feasibility. At the same time, three studies including our own showed that early removal of drains after PD is safe $(11,12)$. Moreover, these results are confirmed by three meta-analyses that demonstrated the feasibility of early drain removal $(5,13,14)$. A recent meta analysis showed that absence of drainage after PD results in similar 
rates of mortality, morbidity and reintervention, but on a very selected population of patients (15).

We therefore decided to conduct a multicenter trial to assess the impact of the timing of removal of $\mathrm{AD}$ on the course of post-PD complications. 


\section{METHODS}

\section{$\underline{\text { Trial design }}$}

This study (DRAINAGE Study) is a phase III multicenter (four university hospitals and one general hospital), randomized, open-label, intention-to-treat, superiority clinical trial conducted from June 2011 to December 2015.

\section{$\underline{\text { Ethical approval }}$}

The trial was approved by an independent ethics committee (CPP Nord Ouest II, CCTIRS and CNIL), supported by French government funding (PHRC A01347-32) and registered on Clinical Trials (NCT01368094). It was conformed to the declaration of Helsinki. All patients provided their informed consent before participating. The study complies with the CONSORT statement.

\section{$\underline{\text { Study population }}$}

Patients treated for pancreatic disease regardless of its nature and requiring PD.

\section{Surgery}

PD was performed by experienced senior surgeons. Pyloric conservation, main pancreatic duct stenting, nature of the pancreato-digestive anastomosis (pancreatogastrostomy or pancreatojejunostomy) and administration of Octreotide (Sandostatine ${ }^{\circledR}$, Novartis) were left to the surgeon's discretion, but this choice of peroperative and postoperative management was homogeneous in each center.

At the end of the surgical procedure, all patients were drained in the right flank ( \pm left flank) with closed drains; either by a module composed of a closed-suction silicon drain and a multichannel silicon drain or a passive-gravity drain and a multichannel silicone drain. 


\section{$\underline{\text { Postoperative course }}$}

After resection, patients were submitted to daily clinical review, with collection of blood samples (complete blood count, serum amylase, CRP) and amylase level in drainage fluid assayed on Postoperative day (POD) 3 and depending on the postoperative course. CT scan was systematic performed on POD3. Patients experiencing postoperative events such as PF, hemorrhage, biliary fistula were excluded, regardless of the proposed management.

Patients were randomized on POD3 in absence of:

- Pancreatic fistula (PF) according the definition of the International Study Group on Pancreatic Fistula (ISGPF) (16)

- Fever, defined as temperature higher than $38^{\circ} \mathrm{C}$

- Intra-abdominal collection confirmed on CT scan

When CT scan was contraindicated, the patient was not included and intraperitoneal drainage was left in place according to the team's usual practice. After randomization, in the presence of deep surgical site infection (SSI), adapted management was proposed including curative antibiotic therapy and/or drainage and/or surgical exploration.

\section{$\underline{\text { Inclusion and exclusion criteria }}$}

Details of inclusion and exclusion criteria are shown in Table 1.

\section{$\underline{\text { Randomization }}$}

Randomization was performed on POD3 by means of an electronic module integrated in an electronic case report form according to a 1:1 ratio (early drainage: standard drainage) and stratified by center, pancreatico-digestive anastomosis (pancreaticojejunostomy $v s$. pancreaticogastrostomy), pancreatic parenchyma texture (soft vs. hard) and drainage 
characteristics ( 1 vs. 2; closed-suction vs. passive-gravity). The size of randomized blocks was randomly attributed to prevent the investigators from predicting the randomization result for the next patient.

\section{Feasibility}

During the trial, all centers prospectively recorded all patients planned for PD and the reasons for non-inclusion. All items are indicated in the CONSORT flowchart (Figure 1).

\section{$\underline{\text { Post-randomization monitoring }}$}

In the experimental arm, all drain modules were removed on POD4 without mobilization and without consideration on the aspect or volume of the output.

In control arm, drains were removed from POD5 in the absence of PF and when drain output was less than $100 \mathrm{~cm}^{3}$ or in the case of PF depending on the appearance of drainage fluid and the patient's clinical status.

\section{Endpoints}

All endpoints including primary and secondary ones are defined in Table 2.

The primary endpoint was the proportion of patients who developed a surgical site infection (SSI) during the first 30 postoperative days (30-day SSI) in both arms (early vs. standard drainage arms). The diagnosis of postoperative infection was based on clinical, biochemical, or morphological features and was confirmed by bacteriological data.

A postoperative SSI was defined as superficial or deep wound infections or organ-space infections, in accordance with Centers for Disease Control and Prevention (CDC) guidelines on the prevention of surgical site infections (17). 
We chose SSI as primary outcome, as amylase levels in drainage fluid cannot be measured in the absence of a drain, but this does not exclude the presence of PF. Furthermore, the use of a drain is not specific for the detection of PF, but can also reveal hemorrhage, biliary fistula or intra-abdominal abscess. Finally, in most studies assessing the impact of drainage after surgery in the available literature on hepatobiliary and pancreatic surgery, SSI is often chosen as primary outcome. In the RCT by Fong et al. (18) including patients undergoing liver resection by laparotomy, the use of drains was compared in terms of deep infections and wound infections. Petrowski et al. (19), in the same population as Fong, also conducted a meta-analysis of the impact of drains in term of intra-abdominal collection. Moreover, Conlon et al. (8), in their RCT in patients undergoing pancreatic tumor resection, evaluated the impact of drainage in terms of deep SSI or intra-abdominal fluid collection and in the study by Kawai (11) evaluating early removal of drains after PD, the primary outcome was SSI.

To ensure comprehensive data collection for the primary endpoint, all notified serious and non-serious adverse events were checked by hand by an independent reviewer (JD) not involved in data collection.

Secondary endpoints were as follows:

- Specific post-pancreatoduodenectomy complications: clinically relevant postoperative PF (CR-POPF) i.e. grade B and C of the 2005 ISGPF classification (16), chyle leak, postoperative hemorrhage, delayed gastric emptying.

- Postoperative morbidity expressed using Clavien and Dindo classification including the rate and reasons for reoperation (20).

- Other postoperative infectious complications including risk factors for SSI.

- $\quad$ Length of drainage. 
- Length of hospital stay.

- Readmission.

During study enrolment, an amendment was made to include patients with chronic pancreatitis to improve the feasibility of study recruitment. This amendment was initiated by the coordinating center and validated by the independent scientific committee.

\section{$\underline{\text { Safety and serious adverse events }}$}

Adverse events were recorded by the investigators during hospitalization or at the 30-day follow-up visit.

\section{Data collection}

Each patient's clinical and biochemical status was monitored during hospitalization. Patients were discharged from hospital when free of pain, fever, and any digestive symptoms. Four weeks after surgery, patients were screened for SSI in the outpatient clinic.

On hospital discharge, the patient's primary care physician was informed about the patient's inclusion in the trial. The presence or absence of a SSI was systematically checked by study investigators at the 4-week follow-up visit. When a SSI was detected before week 4, associated data at the time of occurrence were recorded.

\section{$\underline{\text { Statistical analysis }}$}

In accordance with the literature at the time of the study drawing, an SSI rate of $30 \%$ was expected after PD with abdominal drainage $(3,11,12)$. The study design was based on the hypothesis of a reduction of the SSI rate from $30 \%$ to $10 \%$ in the early arm, with a two-sided 
$\alpha$ risk of 0.05 and a $\beta$ risk of 0.2 , yielding a power of $80 \%$. We calculated that 64 patients were required per arm, for a study population of 124 patients. By assuming that $10 \%$ of patients would not be evaluable, the number of patients to be included was defined as 138 (69 per arm).

All analyses were performed with SAS software (version 9.4., SAS Institute, Cary, NC, USA). Population characteristics are expressed as percentages (95\% confidence interval, (95\%CI)). Qualitative variables including the primary endpoint and most of the secondary endpoints are expressed as numbers (percentages $(95 \% \mathrm{CI})$ ) and quantitative variables are expressed as mean ( \pm standard deviation) or median (range). Between-arm differences were assessed by $\chi 2$ test and Student's t test.

To identify potential risk factors for SSI, logistic regression was performed with the "presence of SSI" variable as dependent variable and potential predictors as independent variables. In the multivariate model, stepwise selection by elimination of variables that did not reach a $\mathrm{p}$ value $<0.1$ according to Wald's statistics was used.

A $p$ value less than 0.05 was considered to be statistically significant. Intention-to-treat and per protocol analyses were performed. 


\section{RESULTS}

Three hundred and fifty-three patients were assessed for eligibility and 141 were randomized (71 in the early arm vs. 70 in the standard arm) (feasibility=39.9\%) (Figure 1).

Only one patient was excluded because of the presence of a collection in the systematic CT scan at POD3.

The two arms were well balanced in terms of medical history except for chronic obstructive pulmonary disease (COPD) and preoperative biliary drainage (PBD), which were more frequently observed in the early arm $(8.4 \%$ vs. $0 \%$ and $52.1 \%$ vs. $35.7 \%$, respectively). The main indication for PD was pancreatic adenocarcinoma (70.2\%) (Table 3).

Surgical characteristics and details on drainage are given in Table 4. No statistically significant difference was observed between arms in terms of surgical management. At the end of surgery, a right drainage module was placed in all patients and an additional left drainage module was placed in 93 patients $(66 \%)$ with no statistically significant difference between arms.

\section{$\underline{\text { Primary endpoint }}$}

Among the 141 patients considered for analysis, 27 patients (19.1\%) experienced a SSI during the first 30 postoperative days, with no statistically significant difference between early $(14.1 \%)$ and standard drainage $(24.3 \%)(\mathrm{p}=0.12)$.

Only the deep SSI rate was lower in early group (2.8\%) than in the standard group $(17.1 \%)$. The superficial SSI rate was similar between groups (8.5\% vs. $7.1 \%)$.

\section{$\underline{\text { Secondary endpoints }}$}


All secondary endpoints are reported in Table 5.

Specific post-pancreatoduodenectomy complications:

Twelve (8.5\%) patients developed PF: $3(4.2 \%)$ in the early drainage arm and $9(12.8 \%)$ in the standard drainage arm with no statistically significant difference between arms $(\mathrm{p}=0.07)$. The CR-POPF rate was $5.7 \%$.

Only amylase leak (grade A PF) were significantly less frequent in the early arm (0 (0\%) vs. 4 (5.7\%), $\mathrm{p}=0.04)$. Details on PF management are presented in Table 6.

\section{Postoperative morbidity:}

The overall postoperative morbidity was $80.8 \%$. Overall severe morbidity, i.e. Clavien score $\geq$ III, was $17.7 \%$ and statistically similar between early (14.0\%) and standard arms $(21.4 \%)$ $(\mathrm{p}=0.25)$. The mortality rate was $1.4 \%$ ( 1 death per arm, $\mathrm{p}=0.99)$. The overall reoperation rate was $7.8 \%$ (7.0\% in the early arm vs. $8.6 \%$ in the standard arm, $\mathrm{p}=0.73)$.

\section{Risk factors of postoperative infectious complications}

All preoperative and surgical characteristics were tested as risk factors of SSI and none of them were found to be predictive of SSI. Moreover, neither the timing of drain removal (early $v s$. standard drainage $)(\mathrm{OR}=0.74(95 \% \mathrm{CI} 0.35-1.13, \mathrm{p}=0.38)$, nor the number of drains $(1 v s$. >1) $(\mathrm{OR}=0.87(95 \% \mathrm{CI} 0.70-1.04, \mathrm{p}=0.23)$, nor the type of drain (passive gravity drain $\mathrm{v} s$. closed-suction drain) $(\mathrm{OR}=0.94(95 \% \mathrm{CI} 0.81-1.07, \mathrm{p}=0.49)$, nor the site of drainage (bilateral vs. unilateral) $(\mathrm{OR}=1.36(95 \% \mathrm{CI} 0.88-1.84, \mathrm{p}=0.30)$ were identified as risk factors for SSI.

\section{Length of drainage}

The length of drainage was significantly shorter in the early drainage group $(5 \pm 5.6$ days vs. $11.8 \pm 7.5$ days, $\mathrm{p}<0.01$ ). Only 4 patients in the early group had their drain left in place after POD4 leading to a median length of drainage of 5 days, but 67 patients had their drain 
removed on POD4 resulting in a high applicability rate of 93\%. In the standard group, the drain was removed from POD5, but was left in place longer in most of cases because of the volume and the aspect of the drain output, leading to a mean time of removal of 11.8 days and an applicability rate of $97 \%$.

\section{Length of stay}

The length of hospital stay was statistically reduced in the early group (17.8 \pm 6.8 days vs. $21.0 \pm 6.8$ days, $\mathrm{p}<0.01$ ). Groups were comparable in terms of the readmission rate, which was $2.1 \%(2.8 \%$ vs. $1.4 \%, \mathrm{p}=0.57)$. 


\section{DISCUSSION}

The place of abdominal drainage is still the subject of heated discussion, but the real surgical practice evaluation survey of IHPBA (International Hepato Pancreato Biliary Association) members reported by Melloul et al. (6) showed that drainage was performed after PD in 90\% of cases in 2013.

The DRAINAGE study showed a twofold higher SSI rate in the standard drainage group (14.1\% vs. $24.3 \%)$, although this result was not significant. Furthermore, early removal of drains was associated with a significantly lower deep SSI rate $(2.8 \%$ vs. $17.1 \%)$ resulting in a shorter length of stay (17.8 days vs. 21.0 days) without influencing PF, reoperation and readmission rates. On multivariate analysis, drainage modality was not identified as a risk factor for SSI in a selected population of patients without PF on POD3.

The feasibility of the protocol was about $40 \%$ over 4 years, and the applicability was very high, about $93 \%$ in the early drainage group and $97 \%$ in the standard drainage group, meaning that protocole is highly reproducible for patients undergoing PD.

The present series of selected patients undergoing PD without PF on POD3 reported an overall PF rate of $8.5 \%$ with low reoperation $(7.8 \%)$ and mortality rates $(1.4 \%)$, consistent with recently published RCT. The length of stay (LOS) in the early drainage group of 17 days needs to be interpreted in the light of the readmission rate $(2.1 \%)$. We are aware that the LOS in our study can be considered high, but this is situated in the same range as those reported by Witzigmann et al. (2) in his no-drain group and shorter than reported by Senda et al. (7).

This RCT failed to demonstrate the superiority of early drain removal on SSI in contrast with the two other prospective studies by Kawai et al. (11) and Bassi et al. (12). First, surprisingly, although the three populations were selected with a low PF risk, the PF rates reported by Kawai and Bassi in the standard drainage group were twofold higher than those reported in 
our study (12.8\% in our study, 23\% in Kawai et al., 26.3\% in Bassi et. al), and comparable with the $21 \%$ PF rate in a population of unselected patients after PD in the series by Keck et al. (1). This difference could be explained by the characteristics of Bassi's population (66\% of patients underwent distal pancreatectomy). The low SSI and PF rates in the standard drainage arm in our series $(24.3 \%$ and $12.8 \%)$ could account for our non-significant results. Secondly, the two arms in our series, differed preoperatively in terms of the proportion of patients who received PBD in the early drainage arm, a well-known factor of postoperative SSI (21-23), which could have been responsible for a higher SSI rate in the early drainage arm. Third, in our study drains were removed depending on the drain amylase on POD3 in contrast with the two studies which has evaluated the early removal of drains after PD which were based on the POD1 amylase level, but our series is consistent with the international definition of PF based on the amylase level on POD 3 published at the time of the study design(16).

Other limitations of our study were that patients with chronic pancreatitis were excluded at the beginning of recruitment, prior to an amendment designed to improve recruitment. Nevertheless, only two patients were excluded before, and only five patients were randomized after the amendment. Surprisingly, inadequate surgical management was sometimes observed, as, among the $67 \%$ of patients with soft pancreas, only $40 \%$ were treated with somatostatin analogs and only $49 \%$ underwent main pancreatic duct stenting. Those results highlight the lack of standardization in the management of patients undergoing PD. This bias is constant in the studies evaluating post PD drainage and it could be interesting to define an integrated care pathway for those patients.

The main strength of our study concerns the homogeneity of the study population (all patients underwent PD, mostly with pancreatojejunostomy), in contrast with other RCT: in the study by Conlon et al. (8), $22.3 \%$ of patients underwent distal pancreatectomy (DP); in the study by Bassi et al. (12) , 65.7\% underwent DP and in the study by Witzigmann et al. (2), 15.4\% 
underwent duodenum-preserving pancreatic head resection. Another important point is the feasibility and the applicability of our results: almost $40 \%$ of patients undergoing PD were concerned over a 4-year period, and more than $93 \%$ of patients in the early group and $97 \%$ of patients in the standard group received the intervention they were allocated to. This result confirmed the feasibility of the RCT evaluating early drain removal after PD (62\% in Bassi et al.). On the contrary, Witzigmann et al. (2) tested the absence of drainage in selected patients, but this modality was applied in only $14 \%$ of patients and almost $21 \%$ of patients in the nodrain group were drained. Finally, our study clearly highlights the improved recovery after surgery, by confirming that the POD3 CT scan, the second drain module (left module) and mobilization of drainage are unnecessary. The type of drain (passive gravity drains or closedsuction drains) remains a hot topic, and is currently under investigation in the DRAPA trial (NCT 01988519).

In summary, omission of drains after PD appears to be an innovative concept that is not currently feasible in routine clinical practice. Abdominal drain placement after PD should be decided on an individual basis, as proposed in the studies by Mc Millan et al. (24,25). Early drain removal after PD could be a first step in surgical practice designed to optimize drainage after PD. In our study, 45 out of 141 patients (30\%) should not have been drained according to their low PF risk. Nevertheless, as far as the patients had drain insertion it is impossible to conclude on any benefit of absence of drainage. 


\section{CONCLUSION}

The DRAINAGE study confirms that early drain removal after PD does not appear to increase or decrease the surgical site infection rate. 


\section{ACKNOWLEDGMENTS}

The authors would like to thank Mrs D. Lignier for her help in collecting data and Mr K.

Dahache for his help in data monitoring. The authors would like to acknowledge the British Library, London, for its assistance to the authors during writing of the manuscript. 


\section{REFERENCES}

1. Keck T, Wellner U. F, Bahra M, et al. Pancreaticogastrostomy versus pancreatojejunostomy for RECOnstruction After PANCreaticoduodenectomy (RECOPANC): perioperative and long-term results of a multicenter randomized controlled trial. Ann Surg. 2016;(263):440-9.

2. Witzigmann H, Diener MK, Kienkötter S, et al. No need for routine drainage after pancreatic head resection: the dual-center, randomized, controlled PANDRA trial. Ann Surg. 2016;(264):528-37.

3. Fuks D, Piessen G, Huet E, et al. Life-threatening postoperative pancreatic fistula (grade C) after pancreaticoduodenectomy: incidence, prognosis, and risk factor. Am J Surg. 2009;197(6):702-9.

4. Kagedan D. J, Ahmed M, Devitt K. S, et al. Enhanced recovery after pancreatic surgery: a systematic review of the evidence. HPB. 2015;17(1):11-6.

5. Peng S, Cheng Y, Yang C, et al. Prophylactic abdominal drainage for pancreatic surgery. Cochrane Database Syst Rev. 2015;8:CD010583.

6. Melloul E, Raptis DA, Clavien PA, et al. Poor level of agreement on the management of postoperative pancreatic fistula: results of an international survey. HPB. 2013;15:30714.

7. Senda Y, Shimizu Y, Natsume S, et al. Randomized clinical trial of duct-to-mucosa versus invagination pancreaticojejunostomy after pancreatoduodenectomy. Br J Surg. 2018; 105(1):48-57

8. Conlon K. C, Labow D, Leung D, et al. Prospective randomized clinical trial of the value of intraperitoneal drainage after pancreatic resection. Ann Surg. 2001;234(4):48793.

9. Correa-Gallego C, Brennan M. F, D'Angelica M, et al. Operative drainage following pancreatic resection: analysis of 1122 patients resected over 5 years at a single institution. Ann Surg. 2013;258(6):1051-8.

10. Lim C, Dokmak S, Cauchy F, et al. Selective policy of no drain after pancreaticoduodenectomy is a valid option in patients at low risk of pancreatic fistula: a case-control analysis. World J Surg. 2013;37(5):1021-7.

11. Kawai M, Tani M, Terasawa H, et al. Early removal of prophylactic drains reduces the risk of intra-abdominal infections in patients with pancreatic head resection: prospective study for 104 consecutive patients. Ann Surg. 2006;244(1):1-7.

12. Bassi C, Molinari E, Malleo G, et al. Early versus late drain removal after standard pancreatic resections: results of a prospective randomized trial. Ann Surg. 2010;252(2):207-14.

13. Van der Wilt AA, Coolsen MM, de Hingh IH, et al. To drain or not to drain: a cumulative meta analysis of the use of routine abdominal drains after pancreatic 
resection. HPB. 2013;15:337-44.

14. Cecka F, Lovecek M, Jon B, et al. Intra-abdominal drainage following pancreatic resection: a systematic review. World J Gastroenterol. 2015;21:11456-8.

15. Huttner FJ, Probst $\mathrm{P}$, Knebel $\mathrm{P}$, et al. Meta-analysis of prophylactic abdominal drainage in pancreatic surgery. BJS. 2017;107:660-8.

16. Bassi C, Dervenis C, Butturini G, et al. Postoperative pancreatic fistula: an international study group (ISGPF) definition. Surgery. 2005;138(1):8-13.

17. Horan T. C, Gaynes R. P, Martone W. J, et al. CDC definitions of nosocomial surgical site infections, 1992: a modification of CDC definitions of surgical wound infections. Am J Infect Control. 1992;20(5):271-4.

18. Fong Y, Brennan M. F, Brown K, et al. Drainage is unnecessary after elective liver resection. Am J Surg. 171(1).

19. Petrowski H, Demartines N, Rousson V, et al. Evidence-based value of prophylactic drainage in gastrointestinal surgery. Ann Surg. 2004;240(6).

20. Dindo D, Demartines N, Clavien P. A. Classification of surgical complications: a new proposal with evaluation in a cohort of 6336 patients and results of a survey. Ann Surg. 2004;240(2):205-13.

21. Furukawa K, Shiba H, Shirai Y, et al. Negative impact of preoperative endoscopic biliary drainage on prognosis of pancreatic ductal adenocarcinoma after pancreaticoduodenectomy. Anticancer Res. 2015;35(9):5079-83.

22. Chen $\mathrm{Y}, \mathrm{Ou} \mathrm{G}$, Lian $\mathrm{G}$, et al. Effect of preoperative biliary drainage on complications following pancreatoduodenectomy: a meta-analysis. Medicine (Baltimore). 2015;94(29):1199.

23. Uemura K, Murakami Y, Satoi S, et al. Impact of preoperative biliary drainage on longterm survival in resected pancreatic ductal adenocarcinoma: a multicenter observational study. Ann Surg Oncol. 2015;22:S1238-46.

24. Mc Millan MT, Malleo G, Bassi C, et al. Drain management after pancreatoduodenectomy: reappraisal of a prospective randomized trial using risk stratification. J Am Coll Surg. 2015;221:798-809.

25. Mc Millan MT, Malleo G, Bassi C, et al. Multicenter, prospective trial of selective drain management for pancreatoduodenectomy using risk stratification. Ann Surg. 2016;265(6): 1209-1218. 


\section{FIGURE LEGENDS}

Table 1. Inclusion and exclusion criteria

Figure 1. Flow chart

Table 2. Definitions

Table 3. Preoperative characteristics

Table 4. Surgical characteristics

Table 5. Details of primary and secondary endpoints

Table 6. Characteristics of patients developing pancreatic fistula 


\section{Figure 1. Flow chart}

* patients "excluded from analysis" correspond to the Per Protocol population. Per Protocol analysis was not performed in this trial;

† Overall PF rate in patients assessed for eligibility: $35.4 \%$;
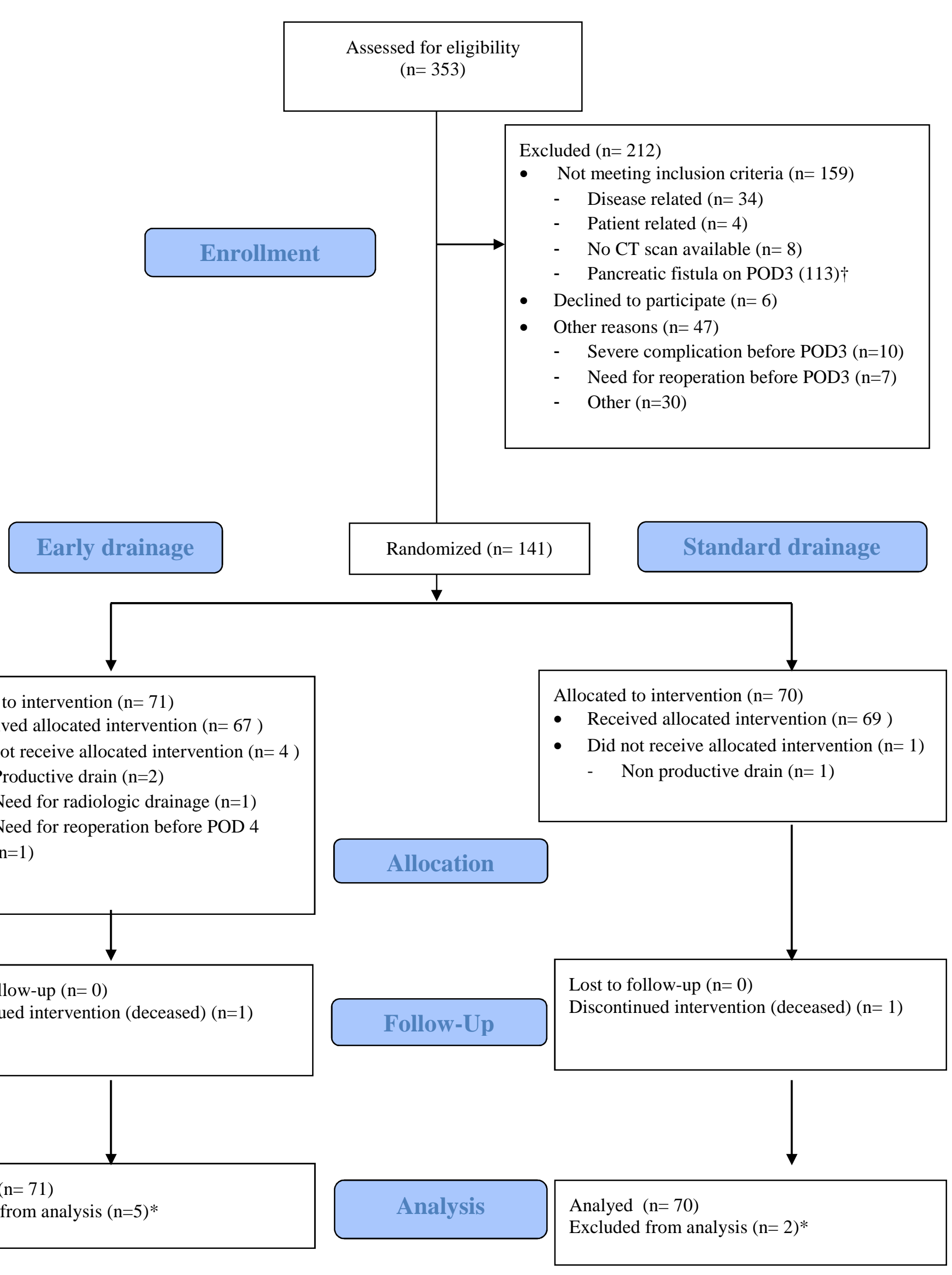

Allocated to intervention $(n=71)$

- Received allocated intervention $(n=67)$

- Did not receive allocated intervention $(n=4)$

- $\quad$ Productive drain $(n=2)$

- $\quad$ Need for radiologic drainage $(n=1)$

- $\quad$ Need for reoperation before POD 4 $(n=1)$

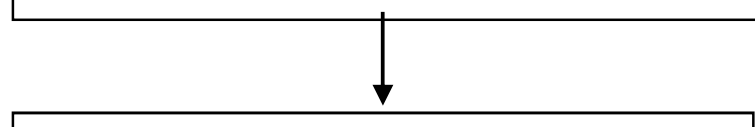

Lost to follow-up $(\mathrm{n}=0)$

Discontinued intervention (deceased) $(\mathrm{n}=1)$
Allocated to intervention $(n=70)$

- Received allocated intervention $(n=69)$

Did not receive allocated intervention $(n=1)$

Non productive drain $(n=1)$

Lost to follow-up $(n=0)$

Discontinued intervention (deceased) $(n=1)$
Analyed $(n=71)$

Excluded from analysis $(\mathrm{n}=5)^{*}$
Excluded from analysis $(n=2) *$ 
Table 1. Inclusion and exclusion criteria

\section{Inclusion criteria}

Disease-related

- Pancreatic tumor regardless of its nature

- All patients requiring PD (according to guidelines or multidisciplinary team recommendations) for this indication

Patient-related

- 18 years or older

Research-related

- Covered by national health insurance

- Patient information and signature of informed consent form

\section{Exclusion criteria}

Disease-related

- History of pancreatic surgery or biliary diversion and/or digestive

- Patient managed for chronic pancreatitis without tumor *

- History of supramesocolic radiotherapy

- Sick supported emergency

- Extrapancreatic procedure not included in PD (liver resection)

Patient-related

- Contraindication to surgery

- ASA classification (American

Society of Anesthesiologists) IV-V or life expectancy $<48$ hours

- Physical or mental condition preventing participation in the study

- Pregnancy or breastfeeding

Research-related

- Patient under guardianship or deprived of his/her freedom by a judicial or administrative decision (articles L1121-6 and L1121-8 of the French Public Health Code)

\footnotetext{
* During study enrollment, an amendment was made to include patients managed for chronic pancreatitis without tumor to improve the feasibility of study recruitment
} 
Surgical site infection (SSI): superficial or deep infections or organ-space infections, in accordance with Centers for Disease Control and Prevention (CDC) guidelines on the prevention of SSI.

Wound infection: SSI with at least one of the following criteria: (1) occurrence within 30 days of the surgical procedure, and (2) involvement of only skin or subcutaneous tissue around the incision but with at least 1 of the following: purulent drainage from the superficial incision; organisms isolated from an aseptically obtained culture of fluid or tissue from the superficial incision; 1 or more of the following signs or symptoms: pain or tenderness, localized swelling, redness or heat and opening of the superficial incision by the surgeon unless the culture of the incision tested negative for infection, diagnosis of a superficial incisional surgical site infection by the surgeon or attending physician.

Other infections: pulmonary (presence of clinical or laboratory signs of inflammation and localized lung infection) and urinary (presence of clinical symptoms and laboratory signs of inflammation associated with positive urinary cytology) infections, bacteremia (presence of $\geq 1$ positive hemoccult to the same pathogen), and lymphangitis.

Intra-abdominal abscess: Fluid collection with positive cultures and persistent fever/elevated leukocyte count, both diagnosed by transabdominal ultrasound or CT scan.

Pancreatic fistula (PF): Any output with high amylase content (> 3-fold serum amylase) (ISGPF definition with clinical grading system [A, B, C]) [12]

Chyle leak: Output of chylous ascites from drains, with high fat (triglyceride) content.

Postoperative hemorrhage: Blood loss through abdominal drains or nasogastric tube; hematemesis or melena; clinical deterioration of the patient; unexplained hypotension or tachycardia or laboratory findings such as decreasing hemoglobin concentration (ISGPS definition with clinical grading system $[\mathrm{A}, \mathrm{B}, \mathrm{C}])$

Delayed gastric emptying: Inability to return to a standard diet by the end of the first postoperative week with prolonged nasogastric intubation (ISGPS definition with clinical grading system [A, B, C])

Reoperation: Need for surgical reoperation within 30 days postoperatively

Length of stay: Time spent in hospital from POD0 to the day of discharge.

Readmission: Need for hospital stay after discharge during the first 30 postoperative days .

Clavien \& Dindo Classification: Morbidity scale based on the therapeutic consequences of complications (Grade I: any deviation from the normal postoperative course, Grade II: use of pharmacological treatment, Grade III: complications requiring surgical, endoscopic or radiological intervention, Grade IV: life-threatening complications requiring intensive care unit management, Grade $\mathrm{V}$ : complications responsible of death)

Callery score: Clinical score based on four criteria (gland texture, pathology, main pancreatic duct diameter and intraoperative blood loss) predicting the development of CR-POPF after PD with risk stratification (0 points Negligible risk, 1-2 points Low risk, 3-6 points Intermediate risk, 7-10 points High risk)

ISGPS: International Study Group of Pancreatic Surgery

ISGPF: International Study Group of Pancreatic Fistula 
Table 3. Preoperative characteristics

\begin{tabular}{|c|c|c|}
\hline & $\begin{array}{c}\text { Early drainage } \\
\quad(\mathrm{n}=71)\end{array}$ & $\begin{array}{l}\text { Standard drainage } \\
(\mathrm{n}=70)\end{array}$ \\
\hline Age, years, mean $\pm \mathrm{SD}$ & $64.1 \pm 10.2$ & $64.5 \pm 8.9$ \\
\hline Male, n (\%) $(95 \% \mathrm{CI})$ & $31(43.7)(32.2-55.2)$ & $23(32.9)(21.9-43.9)$ \\
\hline Weight, $\mathrm{kg}$, mean $\pm \mathrm{SD}$ & $69.6 \pm 14.9$ & $74.3 \pm 16.0$ \\
\hline Body mass index, $\mathrm{kg} / \mathrm{m}^{2}$, mean $\pm \mathrm{SD}$ & $24.7 \pm 4.9$ & $25.7 \pm 4.8$ \\
\hline Pancreatic adenocarcinoma, n (\%) (95\%CI) & $53(74.7)(64.6-84.8)$ & $46(65.7)(54.5-76.9)$ \\
\hline Intraductal papillary mucinous neoplasms, $\mathrm{n}(\%)(95 \% \mathrm{CI})$ & $4(5.6)(0.25-10.9)$ & $7(10.0)(3-17)$ \\
\hline Distal bile duct carcinoma, n (\%) $(95 \% \mathrm{CI})$ & $4(5.6)(0.25-10.9)$ & $4(5.7)(0.4-11)$ \\
\hline Periampullary carcinoma, $\mathrm{n}(\%)(95 \% \mathrm{CI})$ & $3(4.2)(0-8.9)$ & $6(8.6)(2-15.2)$ \\
\hline Chronic pancreatitis, n (\%) $(95 \% \mathrm{CI})$ & $3(4.2)(0-8.9)$ & $2(2.9)(0-6.8)$ \\
\hline Other, $\mathrm{n}(\%)(95 \% \mathrm{CI})$ & $2(2.8)(0-6.6)$ & $3(4.3)(0-9.1)$ \\
\hline Neuroendocrine tumor, $\mathrm{n}(\%)(95 \% \mathrm{CI})$ & $1(1.4)(0-4.1)$ & $1(1.4)(0-4.2)$ \\
\hline Cystic dystrophy in heterotopic pancreas, n (\%) (95\% CI) & $1(1.4)(0-4.1)$ & $1(1.4)(0-4.2)$ \\
\hline Active smoker, n (\%) $(95 \% \mathrm{CI})$ & $27(38.6)(27.3-49.9)$ & $28(40)(28.5-51.5)$ \\
\hline Diabetes mellitus, n (\%) $(95 \% \mathrm{CI})$ & $19(26.8)(16.5-37.1)$ & $26(37.1)(25.8-48.4)$ \\
\hline Chronic kidney failure, n (\%) $(95 \% \mathrm{CI})$ & $1(1.4)(0-4.1)$ & $0(0.0)(-)$ \\
\hline Immunosuppressive drugs, $\mathrm{n}(\%)(95 \% \mathrm{CI})$ & $3(4.2)(0-8.9)$ & $5(7.1)(1.1-13.1)$ \\
\hline Angina, myocardial infarction, $\mathrm{n}(\%)(95 \% \mathrm{CI})$ & $8(11.3)(3.9-18.7)$ & $6(8.6)(2-15.2)$ \\
\hline Peripheral artery disease, $\mathrm{n}(\%)(95 \% \mathrm{CI})$ & $1(1.4)(0-4.1)$ & $2(2.9)(0-6.8)$ \\
\hline $\begin{array}{l}\text { Chronic obstructive pulmonary disease, } \mathrm{n}(\%) \\
\qquad(95 \% \mathrm{CI})\end{array}$ & $6(8.4)(2-14.9)$ & $0(0)(-)$ \\
\hline Weight loss during the last 6 months, $\mathrm{kg}$, mean \pm SD & $8.6 \pm 4.1$ & $9.7 \pm 4.3$ \\
\hline Biliary drainage in jaundiced patient, $\mathrm{n}(\%)(95 \% \mathrm{CI})$ & $37(52.1)(40.5-63.7)$ & $25(35.7)(24.4-48.7)$ \\
\hline Preoperative biopsy, n $(\%)(95 \% \mathrm{CI})$ & $44(62.0)(50.7-73.3)$ & $44(62.9)(51.6-74.2)$ \\
\hline Neoadjuvant chemotherapy, n (\%) (95\%CI) & $8(11.3)(3.9-18.7)$ & $10(14.3)(6.1-22.5)$ \\
\hline $\begin{array}{c}\text { Preoperative immunonutrition }\left(\text { Oral Impact }{ }^{\circledR}\right), \mathrm{n}(\%) \\
(95 \% \mathrm{CI})\end{array}$ & $63(88.7)(81.3-96.1)$ & $61(87.1)(79.2-94.9)$ \\
\hline Normal preoperative serum bilirubin, $\mathrm{n}(\%)(95 \% \mathrm{CI})$ & $37(52.1)(40.5-63.7)$ & $33(47.1)(35.4-58.8)$ \\
\hline Serum albumin $<35 \mathrm{~g} / \mathrm{L}, \mathrm{n}(\%)(95 \% \mathrm{CI})$ & $10(14.8)(6.5-23.1)$ & $18(25.7)(15.3-35.9)$ \\
\hline Blood leukocytes, $/ \mathrm{mm}^{3}$ (ULN: 10), median (range) & $7300(2960-20930)$ & $7565(5500-19800)$ \\
\hline Serum hemoglobin, g/dL, (ULN: 17$)$, mean \pm SD & $12.4 \pm 1.2$ & $12.6 \pm 1.4$ \\
\hline Serum CRP, mg/L (ULN: 5), median (range) & $19(3-154.6)$ & $17(3-125)$ \\
\hline Serum creatinine, $\mu \mathrm{mol} / \mathrm{L}$ (ULN: 97 ), mean \pm SD & $67.0 \pm 21$ & $71.3 \pm 22.1$ \\
\hline Serum urea, mmol/L (ULN: 6.6), median (range) & $5.82(1.8-13.7)$ & $6.25(2.17-21.41)$ \\
\hline Serum lipase, UI/L (ULN: 57), median (range) & $106(5-902)$ & $112(7-690)$ \\
\hline Serum amylase, UI/L (ULN: 104), median (range) & $56(13-394)$ & $46(10-183)$ \\
\hline
\end{tabular}

ULN: upper limit of normal 
Table 4. Surgical characteristics

\begin{tabular}{|c|c|c|}
\hline & $\begin{array}{l}\text { Early drainage } \\
\quad(\mathrm{n}=71)\end{array}$ & $\begin{array}{c}\text { Standard drainage } \\
(\mathrm{n}=70)\end{array}$ \\
\hline \multicolumn{3}{|l|}{ Surgical approach, $n(\%)(95 \%$ CI) } \\
\hline Laparotomy & $69(97.2)(93.4-100)$ & $69(98.6)(95.8-100)$ \\
\hline Laparoscopy & $2(2.8)(0-6.6)$ & $1(1.4)(0-4.2)$ \\
\hline \multicolumn{3}{|l|}{ Pancreatic parenchyma, $n(\%)(95 \%$ CI $)$} \\
\hline Soft / hard & $\begin{array}{c}47(66.2)(55.2-77.2) / \\
24(33.8)(22.8-44.8)\end{array}$ & $\begin{array}{c}47(67.1)(56.1-78.1) / \\
23(32.9)(21.9-43.9)\end{array}$ \\
\hline Main pancreatic duct diameter $<3 \mathrm{~mm}$ & $20(28.2)(17.7-38.7)$ & $19(27.1)(16.7-37.5)$ \\
\hline Main pancreatic duct stenting & $36(50.7)(39.1-62.3)$ & $33(47.1)(35.4-58.9)$ \\
\hline Pyloric conservation, $n(\%)(95 \% C I)$ & $10(14.1)(5.9-22.1)$ & $9(12.9)(5.1-20.8)$ \\
\hline Venous resection, $n(\%)(95 \% C I)$ & $12(16.9)(8.2-25.6)$ & $12(17.1)(8.3-25.9)$ \\
\hline Arterial resection, $n(\%)(95 \% C I)$ & $2(2.8)(0-6.6)$ & $0(0)(-)$ \\
\hline Omentoplasty, $n(\%)(95 \% C I)$ & $50(70.4)(59.8-81.0)$ & $45(64.3)(53.1-75.5)$ \\
\hline \multicolumn{3}{|l|}{ Pancreatic anastomosis, $n(\%)(95 \%$ CI) } \\
\hline Pancreatojejunostomy & $66(93)(87.1-98.9)$ & $63(90)(82.9-97.0)$ \\
\hline Pancreatogastrostomy & $5(7)(1.1-12.9)$ & $7(11)(2.9-17.1)$ \\
\hline \multicolumn{3}{|l|}{ Drainage, $n(\%)(95 \% C I)$} \\
\hline $1 / 2$ modules & $\begin{array}{c}21(29.6)(18.9-40.2) / \\
50(70.4)(59.8-81.0)\end{array}$ & $\begin{array}{c}27(38.6)(27.2-50) / 43 \\
\quad(61.4)(49.9-72.8)\end{array}$ \\
\hline suction / non-suction drain & $\begin{array}{c}54(76.1)(66.2-86.0) / \\
17(23.9)(13.9-33.8)\end{array}$ & $\begin{array}{c}57(81.4)(72.3-90.5) / \\
13(18.6)(9.5-27.7)\end{array}$ \\
\hline Operating time, min, median (range) & $382(202-600)$ & $404(175-886)$ \\
\hline Blood loss, $m L$, median (range) & $475(100-2800)$ & $525(100-3000)$ \\
\hline Somatostatin analog, $n(\%)(95 \% C I)$ & $29(41.4)(29.9-52.9)$ & $27(38.6)(27.2-50)$ \\
\hline
\end{tabular}


Table 5. Details of primary and secondary endpoints

\begin{tabular}{|c|c|c|}
\hline & $\begin{array}{l}\text { Early drainage } \\
\quad(\mathrm{n}=71)\end{array}$ & $\begin{array}{l}\text { Standard drainage } \\
(\mathrm{n}=70)\end{array}$ \\
\hline 30-day surgical site infection, n (\%) (95\%CI) & $10(14.1)(5.9-22.1)$ & $17(24.3)(14.3-34.3)$ \\
\hline \multicolumn{3}{|l|}{ Specific complications, $n(\%)(95 \%$ CI) } \\
\hline Pancreatic fistula & $3(4.2)(0-8.9)$ & $9(12.8)(4.9-20.6)$ \\
\hline CR-POPF (grade B and C) & $3(4.2)(0-8.9)$ & $5(7.4)(1.3-13.5)$ \\
\hline Amylase leak (grade A PF) & $0(0)(-)$ & $4(5.7)(0.3-11.1)$ \\
\hline Chyle leak & $4(5.6)(0.3-10.9)$ & $14(20.0)(10.6-29.4)$ \\
\hline Postoperative hemorrhage & $2(2.9)(0-6.8)$ & $2(2.8)(0-6.7)$ \\
\hline Delayed gastric emptying & $11(14.5)(6.3-22.7)$ & $20(28.6)(18.0-39.2)$ \\
\hline \multicolumn{3}{|l|}{ Clavien score, $n(\%)(95 \% C I)$} \\
\hline $0-$ II & $61(85.9)(77.8-85.9)$ & $55(78.6)(68.9-88.2)$ \\
\hline III - IV & $9(12.7)(4.9-20.4)$ & $14(20)(10.6-29.4)$ \\
\hline $\mathrm{V}$ & $1(1.4)(0-4.1)$ & $1(1.4)(0-4.2)$ \\
\hline$\geq$ III & $10(14)(5.9-22.1)$ & $15(21.4)(11.8-31.0)$ \\
\hline \multicolumn{3}{|l|}{ Other postoperative infectious complications } \\
\hline Superficial surgical site infection, n (\%) $(95 \% \mathrm{CI})$ & $6(8.5)(2-14.9)$ & $5(7.1)(1.1-13.1)$ \\
\hline Deep surgical site infection, n (\%) (95\%CI) & $4(2.8)(0-6.6)$ & $12(17.1)(8.3-25.9)$ \\
\hline Pulmonary complication, n (\%) (95\%CI) & $3(4.2)(0-8.9)$ & $8(11.4)(3.9-18.8)$ \\
\hline Urinary complication, $\mathrm{n}(\%)(95 \% \mathrm{CI})$ & $5(7.0)(1.1-12.9)$ & $5(7.1)(1.1-13.1)$ \\
\hline Catheter infection, n (\%) (95\%CI) & $4(5.6)(0.3-10.9)$ & $4(5.7)(0.3-11.1)$ \\
\hline Poorly controlled diabetes, $\mathrm{n}(\%)(95 \% \mathrm{CI})$ & $2(2.8)(0-6.6)$ & $4(5.7)(0.3-11.1)$ \\
\hline Reoperation rate, $n(\%)(95 \% C I)$ & $5(7.0)(1.1-12.9)$ & $6(8.6)(2.0-15.2)$ \\
\hline Length of stay, days, median (range) & $17.8 \pm 6.8(9-37)$ & $21.0 \pm 6.8(10-53)$ \\
\hline Readmission rate, $n(\%)(95 \% C I)$ & $2(2.8)(0-6.6)$ & $1(1.4)(0-4.2)$ \\
\hline
\end{tabular}


Table 6. Characteristics of patients developing pancreatic fistula

\begin{tabular}{|c|c|c|c|}
\hline $\begin{array}{l}\text { Initial drain } \\
\text { management }\end{array}$ & $\begin{array}{l}\mathrm{PF} \\
\text { diagnosis }\end{array}$ & $\begin{array}{l}\text { Grad } \\
\text { ing } \\
\text { of PF }\end{array}$ & PF management \\
\hline Removed on POD 4 & POD 13 & $\mathrm{C}$ & Reoperation POD 13 \\
\hline Removed on POD 4 & POD 23 & $\mathrm{~B}$ & Conservative \\
\hline Removed on POD 4 & POD 9 & B & Conservative \\
\hline Removed on POD 15 & POD 10 & $\mathrm{~B}$ & $\begin{array}{l}\text { Conservative, } \\
\text { drain removed on POD } 15\end{array}$ \\
\hline Removed on POD 13 & POD 7 & B & $\begin{array}{l}\text { Conservative, } \\
\text { drain removed on POD } 13\end{array}$ \\
\hline Removed on POD 32 & POD 12 & $\mathrm{~B}$ & $\begin{array}{l}\text { Endoscopic management on POD 27, } \\
\text { drain removed on POD } 32\end{array}$ \\
\hline Removed on POD 53 & POD 26 & $\mathrm{~B}$ & $\begin{array}{l}\text { Reoperation POD 26, } \\
\text { drain removed on POD } 53\end{array}$ \\
\hline Removed on POD 21 & POD 15 & A & $\begin{array}{l}\text { Conservative, } \\
\text { drain removed on POD } 21\end{array}$ \\
\hline Removed on POD 29 & POD 7 & $\mathrm{~B}$ & $\begin{array}{l}\text { Conservative, } \\
\text { drain removed on POD } 29\end{array}$ \\
\hline Removed on POD 13 & POD 13 & $\mathrm{~A}$ & $\begin{array}{l}\text { Conservative, } \\
\text { drain removed on POD } 13\end{array}$ \\
\hline Removed on POD 37 & POD 8 & $\mathrm{C}$ & $\begin{array}{l}\text { Reoperation POD } 9 \text { and POD 17, } \\
\text { drain removed on POD } 37\end{array}$ \\
\hline Removed on POD 17 & POD 35 & $\mathrm{~A}$ & $\begin{array}{l}\text { Conservative, } \\
\text { drain removed on POD } 35\end{array}$ \\
\hline
\end{tabular}

* Callery's Fistula Risk score approximation 